\title{
Migraine: New Views on an Old Theory
}

\author{
John Edmeads
}

\begin{abstract}
"Most of the change we think we see in life is due to truths being in and out of favour".

Robert Frost,

The Black Cottage, 1914.
\end{abstract}

The past few years have fascinated those of us interested in headache, as we watch new and ever more sophisticated techniques applied to the study of migraine. Equally intriguing is the curious way in which this new science has led, not to a new theory of the cause of migraine, but to the resuscitation of one almost totally neglected for the past century.

Early views of migraine were based on clinical intuition. Thomas Willis (1621-1675), primed by Harvey's revelation that the blood circulated, speculated that "meagrim" was caused by painful distention of intracranial blood vessels; and Hoffman (1695) added that this vasodilatation might be due to obstruction of smaller vessels. Parry (1792) reported that the pain of hemicrania could be relieved transiently by compression of the ipsilateral superficial temporal artery, thus implicating the extracranial circulation in the genesis of migraine. That this notion did not originate with Parry, however, it attested by Fordyce's warning in "de Hemicrania" (1758) that surgical section of scalp arteries yielded only temporary succour from headache and could not be considered definitive treatment. Erasmus Darwin in 1796 wondered if whirling a patient with head next to the centre of motion might, by drawing blood from the head, relieve migraine headache.

Thus, by the close of the 18th century there had been established a vascular theory of migraine which attributed the pain to vasodilatation, noted that this dilatation might be in response to another factor, explained a clinical observation (Parry's sign), spawned an unsuccessful surgical therapy, and envisaged a laboratory manoeuvre to test the theory.

The 19th century was marked by heated dispute about the role of the nervous system in causing the vascular changes of migraine. In one arena DuBois-Reymond, Mollendorf, and Eulenberg counter-speculated (without any experimental evidence) about autonomic influences, giving rise to the terms "white" or "sympathicotonic" migraine versus "red" or "angioparalytic" migraine. In another arena the "brain versus blood vessel" battle raged. Airy attributed visual auras to "a temporary suspension of function . . . among the nerve cells of the visual sensorium . . . due to vascular congestion". Latham argued that auras were due to "defective supply of blood to one side of the brain from contraction of the cerebral arteries" caused by overactivity of the sympathetic nerves; ultimately this sympathetic discharge became exhausted, with vasodilatation and headache. Liveing held that auras were caused by "nerve storms", the product of "a discharging lesion of convolutions evolved out of the optic thalamus", and that all else was secondary. Influential authorities, including Gowers and Hughlings Jackson, moved into the neurogenic camp. Moebius attempted to mediate by stating that though vascular changes were important in migraine, they were initiated by the nervous system - a view epitomized by his remarkably prescient aphorism, "parenchyma is the master, circulation the servant".

In the first seven decades of the 20th century the vascular theory of migraine gained predominance through four major developments, and the neurogenic theory was eclipsed. These developments were:

1. Maier's demonstration in 1926 that a vasoactive substance, ergotamine, could terminate an attack of migraine.

2. The laboratory research of Wolff and his school (1938 to 1963) which, most inadequately, can be summarized as follows:

a) Evidence that migraine auras are produced by cerebral ischemia, demonstrated by their abolition with cerebral vasodilators such as amyl nitrite and carbon dioxide.

b) Evidence that the headache of migraine is associated with extracranial vasodilatation and that pain relief from ergotamine with extracranial vasoconstriction, as shown by the classic tambour experiments of Graham and Wolff (1938).

c) Evidence that a chemical "pain-threshold lowering substance" is involved in migraine headache, demonstrated by the failure of heat induced vasodilatation alone to produce headache, but with headache occurring after injection of blister fluid around the dilated arteries.

3. Measurements of regional cerebral blood flow ( $\mathrm{rCBF}$ ) in migraine (1967-present) which showed that:

a) $\mathrm{rCBF}$ is reduced during migraine auras, occasionally to levels critical for the adequate oxygenation of brain tissue; this ischemia does not always involve cerebral areas appropriate to the clinical manifestations of the aura, and it may outlast the aura, intruding into the headache phase (Hachinski, Olesen, Norris et al., 1977).

b) Cerebrovascular reactivity to $\mathrm{CO} 2$ and changes in blood pressure is impaired in patients during a migraine 
attack (Sakai, F., and Meyer, J.S., 1979).

c) rCBF and extracranial blood flow is often but not always increased during the headache phase of attacks of classic migraine; $\mathrm{rCBF}$ appears not to be altered during attacks of common migraine (Olesen, J., TfeltHansen, P., Henriksen, L. et al., 1981).

These results appear to support the notion that in classic migraine vasoconstriction produced cerebral ischemia and thus the aura, and that the aura occurred and was prolonged at least in part by the inability of cerebral blood vessels to dilate immediately in response to the hypoxia. A telling point against the concept that the headache was caused by the increased $\mathrm{rCBF}$ was the repeated observation that this cerebral hyperemia could outlast the headache by hours or days.

4. Measurement of changes in the concentration of vasoactive substances in blood (Anthony, M., Hinterberger, H., and Lance, J.W., 1967) and platelets (Gawel, M., Burkitt, M., and Rose, F.C., 1979), prominent among which are observations of decreased blood serotonin levels and increased aggregation of platelets with release of vasoactive and pro-inflammatory substances.

Ironically, it was a study of cerebral blood flow that rescued the neural theory from oblivion. Olesen, Lauritzen et al., (1981), measuring $\mathrm{CBF}$ in 254 areas of one hemisphere, documented that in the aura of classic migraine a front of hyperemia, followed immediately by oligemia, began in the occipital region and spread forward over the cortex at a velocity of about 2 millimeters per minute. They commented that this pattern of spread was not what one would expect to result from spasm of a major cerebral artery; rather, it was reminiscent of the spreading depression of Leao, which is a neurogenic phenomenon (and reminiscent of "a discharging lesion of convolutions evolved out of the optic thalamus"). The similarities between this spreading oligemia, the spreading depression of Leao, the spread of the visual auras across the visual field, and the spread of other migrainous phenomena have been interpreted as suggesting that the vascular changes of migraine are likely secondary to neurological events (Edmeads, 1982).

In ingenious animal experiments Lance and his colleagues (1983) have underscored the possible significance of central neurotransmitters in the production of migraine. In monkeys, low frequency stimulation of the locus caeruleus (which projects noradrenergic fibers to the cortex and its microvasculature) resulted in ipsilateral vasoconstriction in the intracerebral circulation; high frequency stimulation resulted in vasodilatation in the ipsilateral extracranial circulation, vascular changes reminiscent of those occurring in the human in migraine. In the cat (where the internal carotid artery is vestigeal and the common carotid supplies most of the brain), dilatation of the common carotid produced by high frequency stimulation of the locus caeruleus could be prevented by section of the seventh nerve, suggesting that this rapid stimulation of locus caeruleus produced vasodilatation through the facial and greater superficial petrosal pathways. A similar dilatation of the feline common carotid circulation could be evoked reflexly by stimulation of the trigeminal nerve. Lance, on the basis of this data, hypothesized that in classic migraine:

1. Low frequency discharge of the locus caeruleus might affect the cortex directly or constrict its microcirculation, evoking a spreading cortical depression that produces a march of migrainous symptoms and spreading oligemia.

2. Increasing frequency of discharge of the locus caeruleus could induce progressive ipsilateral dilatation of extracranial vessels through the parasympathetic outflow of the seventh cranial nerve.

3. The vasodilatation, if painful, might through stimulation of the trigeminal nerve reflexly produce more dilatation and more pain; the pain might also be due to fatigue of the locus caeruleus (perhaps analogous to the exhaustion suggested by Latham?) with failure of the normal pain modulation effects of the locus caeruleus.

Moskowitz (1979) has also explored the relationship between the trigeminal nerve and the cerebral blood vessels and the possible significance of this to migraine. The cerebral blood vessels are innervated by trigeminal afferent fibers which contain substance P; Moskowitz has demonstrated that substance $\mathbf{P}$ can be released from the sensory terminals of these fibers into the environs of the blood vessels during trigeminal stimulation and speculates:

1. That the capacity of substance $P$ to promote vascular dilatation and permeability may be important in the genesis of migraine.

2. The connections between the brainstem and the trigeminal nerve may allow the central nervous system to modulate the peripheral mechanisms of migraine.

The present flurry of research into migraine continues and we await with excitement the results of further applications of new technology to this old disease. No one can tell where it will end. It seems likely, though, that the scientific innovations will not produce any startingly new theories, but may cause us to re-examine previous concepts and bring old truths back into favour.

\section{REFERENCES}

Anthony M, Hinterberger H, Lance JW (1967) Plasma serotonin in migraine and stress. Arch. Neurol. 16: 544-552.

Edmeads J (1982) Migraine as a model of neurogenic ischemia. Headache 22: $287-288$

Gawel M, Burkitt M, Rose FC (1979) The platelet release reaction during migraine attacks. Headache 19: 323-327.

Lance JW, Lambert GA, Goadsby PJ, Duckworth JW (1983) Brainstem influences on the cephalic circulation: experimental data from cats and monkeys of relevance to the mechanism of migraine. Headache 23: $258-265$.

Graham JR, Wolff HG (1938) Mechanism of migraine headache and action of ergotamine tartrate. Arch. Neurol. Psychiat. 39: 737-763.

Hachinski VC, Olesen J, Norris JW, Larsen B, Enevoldsen E, Lassen NA (1977) Cerebral hemodynamics in migraine. Can. J. Neurol. Sci. 4: 245-249.

Moskowitz MA, Reinhard JF Jr, Romero J, Melamed E, Pettibone DJ (1979) Neurotransmitters and the fifth cranial nerve: is there a relation to the headache phase of migraine? Lancet 2: 883-885.

Olesen J, Lauritzen M, Tfelt-Hansen P, Henriksen L, Larsen B (1982) Spreading cerebral oligemia in classical and normal cerebral blood flow in common migraine. Headache 22: 242-248.

Sakai, F, Meyer JS (1979) Abnormal cerebrovascular reactivity in patients with migraine and cluster headache. Headache 19: 257-266. 